\title{
Programmed cell death pathways in cancer: a review of apoptosis, autophagy and programmed necrosis
}

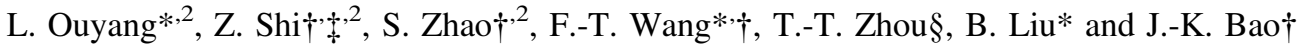 \\ * State Key Laboratory of Biotherapy and Cancer Center, West China Hospital, Sichuan University, Chengdu, China, †Key Laboratory of \\ Bio-resources and Eco-environment, Ministry of Education, School of Life Sciences, Sichuan University, Chengdu, China, $¥$ School of Life Sciences, \\ Guizhou Normal University, Guiyang, China, and §Shanghai Key Laboratory for Pharmaceutical Metabolite Research, School of Pharmacy, \\ Second Military Medical University, Shanghai, China
}

Received 10 March 2012; revision accepted 9 July 2012

\begin{abstract}
Programmed cell death (PCD), referring to apoptosis, autophagy and programmed necrosis, is proposed to be death of a cell in any pathological format, when mediated by an intracellular program. These three forms of PCD may jointly decide the fate of cells of malignant neoplasms; apoptosis and programmed necrosis invariably contribute to cell death, whereas autophagy can play either pro-survival or pro-death roles. Recent bulk of accumulating evidence has contributed to a wealth of knowledge facilitating better understanding of cancer initiation and progression with the three distinctive types of cell death. To be able to decipher PCD signalling pathways may aid development of new targeted anti-cancer therapeutic strategies. Thus in this review, we present a brief outline of apoptosis, autophagy and programmed necrosis pathways and apoptosis-related microRNA regulation, in cancer. Taken together, understanding PCD and the complex interplay between apoptosis, autophagy and programmed necrosis may ultimately allow scientists and clinicians to harness the three types of PCD for discovery of further novel drug targets, in the future cancer treatment.
\end{abstract}

\footnotetext{
Correspondence: T.-T. Zhou, Shanghai Key Laboratory for Pharmaceutical Metabolite Research, School of Pharmacy, Second Military Medical University, No. 325 Guohe Road, Shanghai 200433, China. Tel/ Fax: +86-28-85415171; E-mail: ting0618@tom.com; B. Liu, State Key Laboratory of Biotherapy and Cancer Center, West China Hospital, Sichuan University, Chengdu 610041, China. E-mail: liubo2400@163. com and J.-K. Bao, Key Laboratory of Bio-resources and Eco-environment, Ministry of Education, School of Life Sciences, Sichuan University, Chengdu 610064, China. E-mail: jinkubao@126.com 2These authors contributed equally to this work.
}

\section{Introduction: a brief overview of programmed cell death}

Programmed cell death (PCD) may balance cell death with survival of normal cells; the equilibrium becomes disturbed and PCD plays key roles in ultimate decisions of cancer cell fate $(1,2)$. Of note, apoptosis, autophagy and programmed necrosis are the three main forms of PCD, easily distinguished by their morphological differences $(3,4)$. Apoptosis, or type I PCD, was first described by Kerr et al. (5), and is characterized by specific morphological and biochemical changes of dying cells, including cell shrinkage, nuclear condensation and fragmentation, dynamic membrane blebbing and loss of adhesion to neighbours or to extracellular matrix (6). Biochemical changes include chromosomal DNA cleavage into internucleosomal fragments, phosphatidylserine externalization and a number of intracellular substrate cleavages by specific proteolysis $(7,8)$.

Autophagy, or type II PCD, is an evolutionarily conserved catabolic process beginning with formation of autophagosomes, double membrane-bound structures surrounding cytoplasmic macromolecules and organelles, destined for recycling (9-12). In general, autophagy plays a crucial pro-survival role in cell homeostasis, required during periods of starvation or stress due to growth factor deprivation (13). However, there is accumulating evidence that autophagic cells may commit suicide by undergoing cell death and coping with excessive stress, which differs from apoptosis and programmed necrosis $(4,14)$. As 'the Janus role', autophagy controls a myriad of physiological processes including starvation, cell differentiation, cell survival and death (15). Besides apoptosis and autophagy, there exists a type III PCD termed programmed necrosis, which involves cell swelling, organelle dysfunction and cell lysis (16-18). Thus, PCD may play an important role during preservation of 
tissue homoeostasis and elimination of damaged cells, this has profound effects on malignant tissues (4).

\section{Programmed cell death and cancer}

\section{Molecular mechanisms of programmed cell death}

Cancer, a complex genetic disease resulting from mutation of oncogenes or tumour suppressor genes, can be developed due to alteration of signalling pathways; it has been well known to have numerous links to PCD (19). Apoptosis (type I PCD) is the major type of cell death that occurs when DNA damage is irreparable. Two core pathways exist to induce apoptosis, the extrinsic - death receptor pathway and intrinsic - mitochondrial pathway (20). The extrinsic pathway is triggered by binding of Fas (and other similar receptors such as tumour necrosis receptor 1 and its relatives) plasmamembrane death receptor with its extracellular ligand, Fas-L. When death stimuli occur, Fas-L combines with Fas to form a death complex. The Fas/Fas-L composite recruits death domain-containing protein (FADD) and pro-caspase-8, aggregating to become the death-inducing signalling complex (DISC). Consequently, the protein complex activates its pro-caspase- 8 , which proceeds to trigger pro-caspase-3, the penultimate enzyme for execution of the apoptotic process (5). The intrinsic pathway also leads to apoptosis but under the control of mitochondrial pro-enzymes. In both cases if a cell becomes initiated by either extracellular stimuli or intracellular signals, outer mitochondrial membranes become permeable to interneal cytochrome $c$, which is then released into the cytosol. Cytochrome $c$ recruits Apaf-1 and pro-caspase-9 to compose the apoptosome, which downstream triggers a caspase 9/3 signalling cascade, culminating (as concludes the extrinsic pathway) in apoptosis (21). Accumulating evidence has shown that abnormal expression of some key regulatory factors may lead to cancer, indicating the intricate relationships between apoptosis and cancer.

Autophagy is a major, regulated, catabolic mechanism with many links to processes that occur in malignant cells, and highly regulated by some autophagy-related genes (ATGs). It is a crucial mechanism that responds to either extra- or intracellular stress, and can result in cell survival under certain circumstances; however, over-activation of autophagy may result in autophagic cell death (22). When analysing relationships between autophagy and cancer, a common challenge is to determine whether autophagy protects cell survival or contributes to cell death. Autophagy is well known to be crucial for cell survival under extreme conditions, and degradation of intracellular macromolecules provides energy required for minimal cell functioning when nutrients are scarce (23). Consequently, autophagic activation can play a protective role in early stages of cancer progression (24). On the other hand, however, autophagy can perform as a tumour suppressor by activating pro-autophagic genes and blocking anti-autophagic genes in oncogenesis. However, reminiscent of the Roman god Janus, autophagy can also play the reverse part - a pro-tumour role in carcinogenesis - by regulating a number of pathways involving Beclin-1, Bcl-2, Class III and I PI3K, mTORC1/C2 and p53 (24).

Necrosis has always been considered to be almost 'accidental' cell death, a random, uncontrolled process. With the discovery of key mediators of necrotic death such as RIP kinases and PARP, the concept of programmed necrosis has recently been gaining ground. Receptor interacting protein (RIP) kinases, poly(ADPribose) polymerase-1(PARP1), NADPH oxidases and calpains have been identified as potential signalling components of programmed necrosis $(25,26)$. When cells undergo cell death in this way, integrity of the cell membrane is disrupted so that intracellular materials are released into the extracellular milieu, leading to inflammatory responses by immune cells. Ensuing local inflammation induced by programmed necrosis may promote tumour growth. Yet, necrotic cell death may be exploited to eliminate cancer cells $(27,28)$.

\section{Cross-talk amongst apoptosis, autophagy and programmed necrosis}

Apoptosis, autophagy and programmed necrosis bear distinct morphological characteristics and physiological processes; however, there still exist intricate interrelationships between them. Under some circumstances, apoptosis and autophagy can exert synergetic effects, whereas in other situations autophagy can be triggered only when apoptosis is suppressed $(19,29)$. A number of studies have reconciled the notion that autophagy may act either as a guardian or as an executioner, relying on stage of carcinogenesis, the surrounding cellular environment or therapeutic interventions attempted (25). Programmed necrosis is caspase-independent cell death, always triggered as a backup mechanism for apoptosis when caspases are inactivated (30). However, shikonininduced necroptosis can revert to apoptosis in the presence of necrostatin-1 (Nec-1), a specific necroptosis inhibitor. This death mode switch is partially due to conversion from mitochondrial inner membrane permeability to mitochondrial outer membrane permeability (MOMP) (31). Under certain conditions, apoptosis and programmed necrosis are induced simultaneously and deficiency of both apoptosis and necrosis can be found 
in some cancer cells (32). Moreover, programmed necrosis is accompanied by autophagy, but the specific relationship between them remains an enigma (30).

\section{Apoptotic pathways in cancer}

\section{Tumour necrosis factor receptors: Fas and TRAIL}

The death receptor (DR) family which includes tumour necrosis factor receptor TNF-R1, Fas, DR3, TRAIL-R1/2 (DR4/5) and DR6 can initiate the extrinsic pathway leading to apoptosis (33). Similarity between this family's members mainly relies on the receptors' cytoplasmic regions, namely the death domains (DD), which when bound to their appropriate ligands recruit Fas-associated death domain (FADD). When pro-caspase- 8 becomes hydrolysed into active caspase-8 (death effector domaincontaining protein), the recruited adaptor protein containing death-effector domain (DED), can interact with DED of pro-caspases-8-10, thus aggregating as a DISC (34). When stimuli occur as Fas combines with Fas-L, death complex recruiting FADD and pro-caspase-8, formation of the DISC is initiated to activates caspase- $8(35,36)$ (Fig. 1a).

\section{Bcl-2 family}

The Bcl-2 family includes key regulators of apoptosis and the molecule is over-expressed in many types of cancer cell (37). While reduced Bcl-2 expression may promote apoptotic responses to anticancer drugs, increased expression of $\mathrm{Bcl}-2$ leads to resistance to chemotherapeutic drugs and radiation therapy. The whole $\mathrm{Bcl}-2$ family is comprised of a number of pro-apoptotic members such as Bax, Bak, Bad, Bcl- $X_{S}$, Bid, Bik, Bim and Hrk, plus further anti-apoptotic members such as Bcl-2, Bcl- $\mathrm{X}_{\mathrm{L}}$, Bcl-W, Bfl-1 and Mcl-1 (38). Following a death signal, pro-apoptotic proteins are able to undergo post-translational modifications that include dephosphorylation and cleavage leading to their activation and translocation to mitochondria, from which apoptosis can be initiated (39). All BH3-only molecules require multi-domain $\mathrm{BH} 3$ proteins (Bax and $\mathrm{Bak}$ ) to apply their intrinsic pro-apoptotic activities. These lead

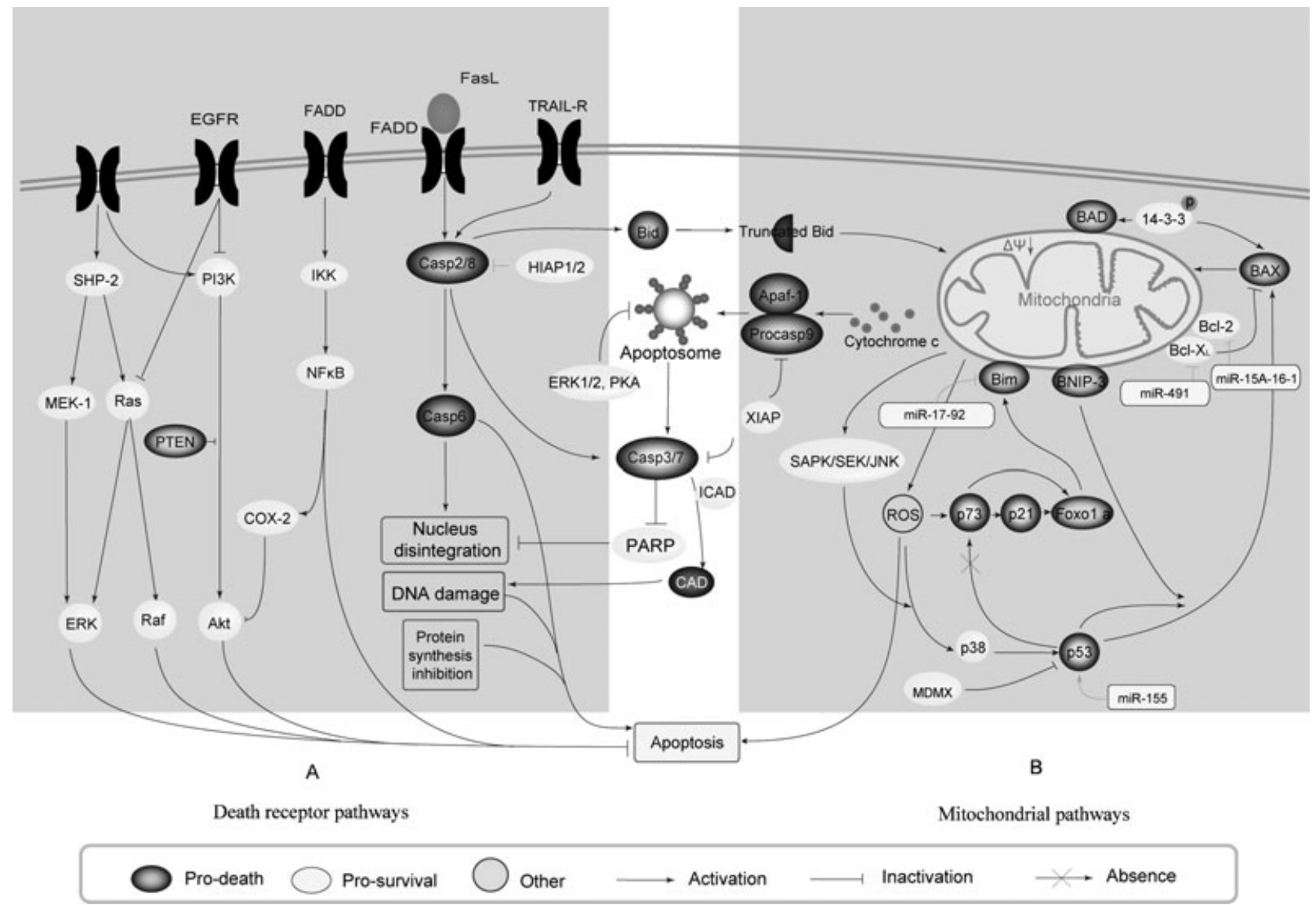

Figure 1. Apoptotic signalling pathways and their relevance to microRNA regulation in cancer. 
to release of cytochrome $c$ and secondly mitochondriaderived activator of caspases; the outer mitochondrial membrane becomes permeable in response to apoptotic stimuli, while cytochrome $c$ can interact with Apaf-1 once released into the cytosol, leading to activation of caspase-9 (40). Activated caspase-9 activates caspase-3, subsequently activating the downstream caspase cascade finally generating apoptosis (Fig. 1b).

\section{Apaf-1 and cytochrome $c$}

Caspase-9 is one of the most representative initiators of mitochondrial apoptosis. Facing apoptotic stimuli, for example agents that induce DNA damage or inhibit DNA repair, pro-apoptotic BH3-only proteins Bim, Bid and Bad can be activated, and promoting oligomerization of p53 effector Bax/Bak, permeabilization of the mitochondrial outer membrane, then release of factors from the intermembrane space $(41,42)$. However, prosurvival Bcl-2 family members Bcl-2, Bcl- $\mathrm{X}_{\mathrm{L}}$, and Mcl1 may be able to counteract this effect (43).

It has been observed and recorded that caspase-2, containing a caspase recruitment (CARD) domain and multi-protein complex, may act upstream of mitochondrial permeabilization by cleaving and activating Bid, playing an important role when DNA damage has induced apoptosis (44). However, it may be that further functions of caspase- 2 in apoptosis remain to be discovered. In the cytoplasm, cytochrome $c$ binding to apoptotic peptidase activating factor-1 (Apaf-1) in the presence of dATP or ATP, promotes self-oligomerization of Apaf-1 (45). It is important to observe that both Apaf-1 and caspase-9 contain the protein interaction motif CARD, while Apaf-1 strongly binds caspase-9 through CARD-CARD interactions, leading to formation of a cytoplasmic feature called the apoptosome, then dimerization-induced activation of caspase-9 (46,47).

WDR domains of Apaf-1 recruit downstream executioners caspases-3 and caspase-7 as soon as the core complex is formed and caspase-9 is activated (48). Downstream executioners cleave the targeted key regulatory molecule, as well as structural proteins, for proteolysis to bring about apoptotic cell death (49); it is then that caspase-9 can process these effector caspases and initiate their release from the complex. Recently, it has been demonstrated that active site cysteine in caspase- 9 as well as cleavage site aspartate in caspase-3, are both required for efficient recruitment and activation of caspase-3, while XIAP can bind to Apaf-1, simultaneously, bind and retain active caspase- 3 within the apoptosome, in an Apaf-1-XIAP-caspase-3 complex (50-52) (Fig. 1b).

\section{$N F-\kappa B$}

$\mathrm{NF}-\kappa \mathrm{B}$ is a class of protein with various transcriptional regulatory functions involved in stress responses, cell proliferation, differentiation, apoptosis and tumourigenesis, and significance of $\mathrm{IKK} / \mathrm{NF}-\kappa \mathrm{B}$ in apoptosis has been fully described (21). NF- $\kappa B$ activation is initiated by signal-induced degradation of $\mathrm{I} \kappa \mathrm{B}$ protein, which bind NF- $\kappa B$ acting as its inhibitor, resulting in its inactivation. After degradation of $\mathrm{I} \kappa \mathrm{B}, \mathrm{NF}-\kappa \mathrm{B}$ can acquires the opportunity to enter the cell nucleus where it can perform its transcriptional regulation function and turn on expression of certain appropriate genes to avoid apoptosis (53-55).

IKK is deemed to be the main regulator of activation of the NF- $\kappa \mathrm{B}$ signalling pathway; thus, I $\kappa \mathrm{B}$ phosphorylation is suppressed by activation of IKK, bringing about inactivation of NF- $\mathrm{KB}$ pathways and indirectly promoting apoptosis $(56,57)$. Activation of the IKK/NF- $\kappa B$ signalling pathway leads to induction of target genes that can interfere with the apoptotic process $(58,59)$ (Fig. 1a).

\section{p53}

The nuclear transcription factor p53 can govern main apoptotic signals that mitochondria receive in the intrinsic pathway of apoptosis (60). p53 is an important proapoptotic factor and tumour inhibitor, thus numerous anti-tumour drugs can exert their functions by targeting p53-related signalling pathways. p53 mainly promotes apoptotic cell death by activating a number of positive regulators of apoptosis such as DR-5 and Bax $(61,62)$ (Fig. 1b).

\section{MicroRNAs in apoptosis}

MicroRNAs (miRNAs) belong to a class of conserved short single-stranded non-protein-coding endogenous RNAs, which play pivotal roles in regulation of around $30 \%$ of gene expressions. Some tumour suppressors, such as the miR-15a-miR-16-1, miR-29 and let-7 family, can modulate core apoptotic pathways (63). It has been reported that miR15-a and miR-16-1 target Bcl-2 to induce apoptosis, while Bcl-2 inhibits mitochondrialmediated apoptosis, by influencing oligomerization of $\mathrm{Bax}$ and Bak at the post-transcriptional level. Additionally, over-expression of miR-15a-miR-16-1 in vitro can decrease Bcl-2 operation, then promote apoptosis (64). The miR-29 family contains three isoforms arranged in two clusters: miR-29b-1/miR-29a in chromosome $7 q 32$ and miR-29b-2/miR-29c in chromosome 1q23. Due to its over-expression in malignant cells, miR-15a-16-1 targeting Bcl-2 could regulate intrinsic apoptotic induction 
(64). The let-7 family is a highly conserved group consisting of 12 related members, of which let-7a has been thoroughly investigated as initiating expression of proapoptotic protein Bim a caspase cascade and finally resulting in apoptosis when the let-7 family is overexpressed in lung and breast cancers. Remarkably, let-7a has been reported to target caspase- 3 and eight nucleotides from the $5^{\prime}$ end of let-7a miRNA. The MiR-34 family is a further tumour suppressor, which activates the p53 subnetwork, also promoting apoptosis (65).

Some miRNAs play their regulatory role as oncogenes, including miRNA-21, the miRNA-17-92 cluster, miRNA-221,-222 and miRNA-272,-273, that negatively regulate apoptotic activity to increase the rate of cancer cell proliferation (66). Anti-apoptotic factor miRNA-21 has been found to be the most consistently upregulated miRNA in many types of cancer. It is suggested that it regulates apoptosis by targeting the $P C D \quad 4$ gene (PDCD4), phosphatase and tensin homologue (PTEN) and tropomyosin 1 (TPM1) (67).

Regulation of PDCD4 by miR-21 is correlated with PDCD4 3'-UTR (58). Similar to PDCD4, regulation of PTEN by miR-21 is directed at the $3^{\prime}$-UTR (57). Regulation of PTEN by miR-21 has been observed to increase expression of two proteins, MMP-9 and MMP2 , involved in invasion of normal hepatocytes. In addition, PTEN has been known to be a therapeutic target of many miRNAs, including the miR-17-92 cluster (below), miR-214 (63). MiRNA-21 can also target TPM1, a member of the TPM protein family, which functions as a serpin peptidase inhibitor. In breast cancer, inhibition of miR-21 causes increase in TPM1 protein expression, involved in the $3^{\prime}$-UTR of TPM1. Recently, it has been intimated that the let-7 family possibly co-operates with miR-21, functioning in cancer progression (67).

MiR-17-92 cluster-induced malignancy is closely associated with the gene $c-M y c$, which encodes a basic helix-loop-helix transcription factor, promotes cell proliferation, inhibits apoptosis, induces tumour angiogenesis and co-operates with MYC for accelerating development of lymphomas (68). The two clusters miR-106b-25 including miR-25 and miR-17-92 including miR-92a-1, are involved in the TGF- $\beta$ tumour suppressor pathway as key modulators, by which activation of TGF- $\beta$ is reduced in cancer development $(69,70)$ (Fig. 1).

\section{Autophagic pathways in cancer}

\section{ULK1/2 and Atg13}

In mammals, two homologues of Atg1 (namely ULK1 and ULK2), Atg13 and scaffold protein FIP200 (an orthologue of yeast Atg17), together are able to form a complex, while FIP200 can localize ULK to pre-autophagosomal structures for recruitment of other Atg proteins (71,72). Under some nutrient-rich conditions, Atg13 is hyper-phosphorylated by mTORC1, losing its ability to bind to ULK, and thus inhibiting autophagy (73) (Fig. 2a).

\section{PI3KCI-Akt-mTORC1}

Recently, the PI3KCI-AKT-mTORC1 signalling pathway has been regarded to be the key regulator of a series of cell processes as it can be deregulated by various genetic and epigenetic mechanisms, in a wide range of cancer cells. Thus, when facing regulation of autophagy, cancer cells are often found to contain multiple genetic and epigenetic abnormalities which can be dependent on certain genes that hijack crucial signalling trunk routes, such as the PI3KCI-Akt-mTOR pathway (74-76). The PI3K family contains at least eight proteins with commonly shared sequence homology in their kinase domains; also they may have different substrate specificities and models of regulation (77). The best known members of this group are the four Class I PI3K isoforms $a, b, d$ and $g$, which convert PIP2 into PIP3, and are associated with carcinogenesis (78).

Akt is a protein serine/threonine kinase known to cause leukaemia in mice (79). There are three numbers of the Akt family, with up to $80 \%$ amino acid sequence homology, and all are implicated in development of cancers (80). Although two types of mTOR exist in mammals, here we only focus on mTORC1 which contains a raptor [due to its sensitivity to rapamycin (81). Three major mTORC1-inducing pathways have been described, amongst which two are of the PI3K-Akt pathway. Signalling pathways that promote mTORC1 activity are induced by oncoproteins and/or loss of tumour suppressors, and thus mTORC1-inhibited autophagy is often observed in malignant cells. PI3KCI antagonizes autophagy by activation of the Akt pathway and therefore the former can be activated to generate PI3, 4-diphosphate and PI3, 4, 5-triphosphate. mTORC1 signalling is positively regulated by growth factors via the PI3KCI-Akt pathway (82). mTORC1 is believed to be activated in part by Akt through tuberous sclerosis complex proteins, TSC1 and TSC2, as the TSC1/TSC2 complex is a critical negative regulator of mTORC1 (83) (Fig. 2a).

\section{Ras-Raf-MAPKs}

Ras-Raf-MAPKs are constitutively activated in most melanomas due to mutation in the BRAF gene; Raf kin- 


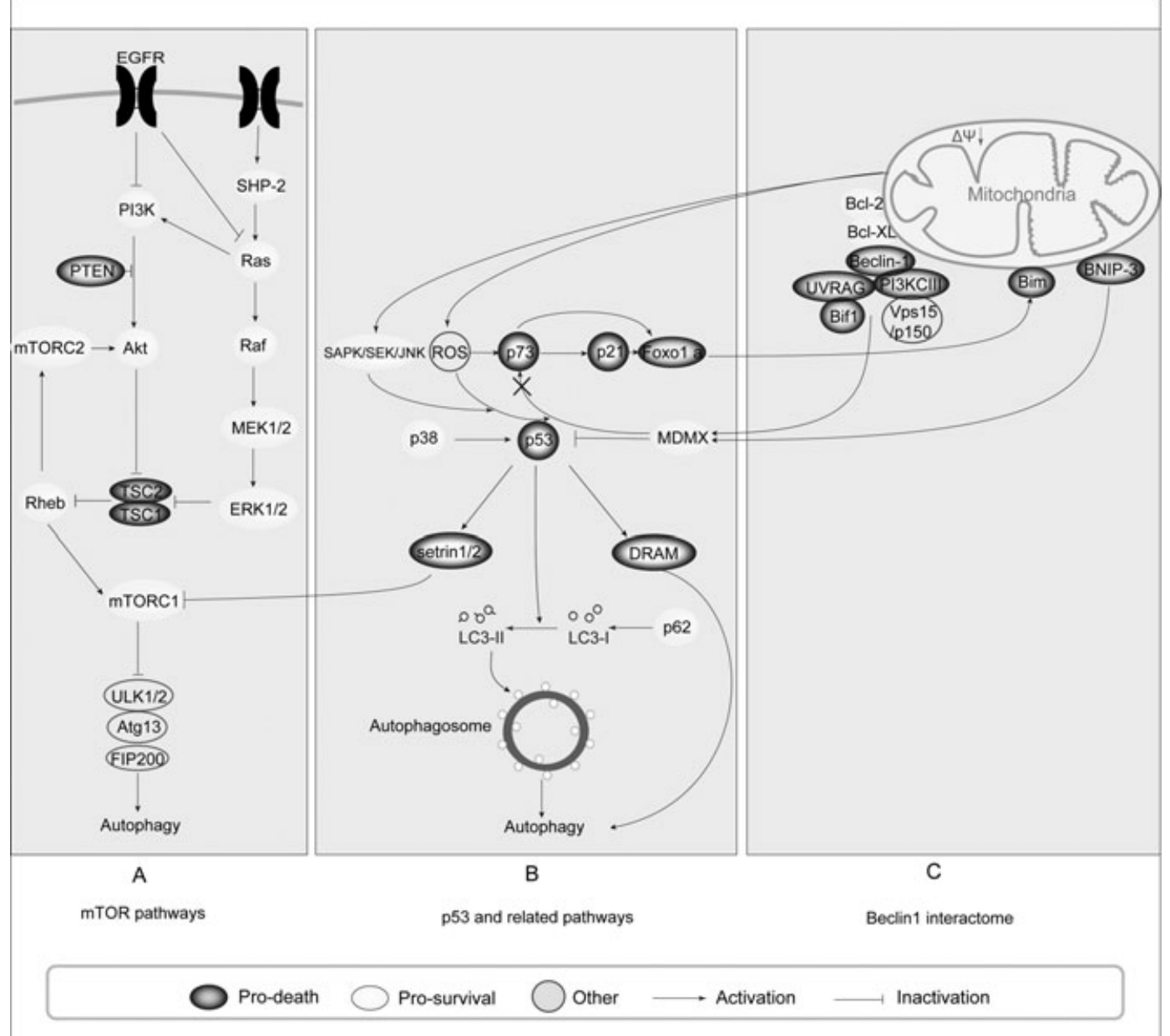

Figure 2. Autophagic signalling pathways in cancer.

ases are regarded as being important in the Ras-RafMAPK signalling pathway $(81,84)$. BRAF mutations may play a crucial role in initiation of human melanomas and sustained Ras-Raf-MAPK signalling may be required for tumour cell survival. In addition, multifunctional protein $\mathrm{pX}$, can activate the Ras-Raf-MAPK pathway as well, while pX-mediated activation of the Ras-Raf-MAPK pathway has been linked to accelerated entry of cells into $S$ phase of the cell cycle $(85,86)$. Activation of the pathway begins when a signal binds to a protein tyrosine kinase receptor. Multiple upstream receptors, including receptor tyrosine kinases, integrins, serpentine receptors, heterotrimeric G-proteins and cytokine receptors, are able to activate K-Ras (87). Then, Raf, a Ras effector as well as a member of the serine/ threonine kinase family, is recruited to the cell membrane by binding to switch I domain of Ras and also by lipid binding (88). Raf activation stimulates a signalling cascade with the aid of phosphorylation of MAPK, which successively phosphorylates and activates downstream proteins ERK1 and ERK2. After Raf activation, serine/threonine kinase MAPK is activated in response to multiple signals such as growth factors in addition to certain cytokines, to promote cell survival and apoptosis through specific mediators, for example JNK, SAPK, 14-3-3 and NF-кB (89) (Fig. 2a).

\section{p53: the Janus role in autophagy}

p53 can be divided into two forms, cytoplasm p53 and nuclear p53, in mammalian cells. In the nucleus, p53 abets autophagy mainly by interacting with its targets, damage-regulated autophagy modulator (DRAM) and sestrin $1 / 2$. DRAM. This is a p53 target gene encoding a lysosomal protein that induces macroautophagy and is found to be an effector of p53-mediated cell death, illustrating the direct link between p53 and autophagy $(15,90)$. DRAM is also a phylogenetically ancient lyso- 
somal protein that functions at the crossroad between p53-induced autophagy and cell death (91). In response to DNA damage agents, DRAM can trigger autophagy under the control of p53. Through direct hypermethylation within itself, expression of DRAM is down-regulated in cells of a subset of epithelial cancers; thus, DRAM can be considered to be tumour suppressor. Sestrin 1 and sestrin 2 are other targets of DRAM, while their expressions are usually induced upon DNA damage and oxidative stress. Genotoxic stress-induced p53dependent up-regulation has also been observed for AMPK activators sestrins1 and 2 (92). The two are both negative regulators of mTORC1 and carry out their functions by activation of AMPK and a TSC complex (93). In addition, disruption of sestrin 2 in mice attenuated its ability to inhibit mTOR signalling (94). Thus, this further molecular mechanism involving serine $1 / 2$, demonstrates a connection between p53 and autophagy, and can be regarded as p53-mediated tumour expression through the mTORC1 signalling pathway. Cytoplasmic p53 has been discovered to inhibit autophagy without assistance of its role as a transcriptional factor (95) (Fig. 2b).

\section{p62, FoxO and NF- $\kappa B$ in autophagy}

p62 has a PB1 domain, a protein-protein interaction module present in other signalling molecules, such as aPKCs and polarity protein Par-6. aPKCs and p62 bind each other through their PB1 domains, and it is the binding that is implicated in activation of transcription factor NF- $\kappa B$, downstream of cell stimulation by interleukin 1 (IL-1), RANK ligand (RANKL), or nerve growth factor (NGF) $(92,96)$.

FoxO1 transcription factors have been implicated in regulating diverse cellular functions such as differentiation, proliferation, metabolism and survival (97). The FoxO subfamily of transcription factors consists of FoxO1, FoxO3 and FoxO4, which are subject inhibition by growth factors, including insulin and IGF-1. As, when under conditions of glucose deprivation, FoxO1 and FoxO3 are dephosphorylated and localized to the cell nucleus, there they activate autophagy pathway gene expression; FoxO1 and FoxO3 promote autophagy pathway gene expression in cardiomyocytes as FoxO1 and FoxO3 directly bind to promoter regions of Gabarapl1 and Atg12, this binding is increased upon cell starvation. Thus, increased FoxO1 and FoxO3 activation can lead to induction of autophagy.

$\mathrm{NF}-\kappa \mathrm{B}$ pathways can be divided into the canonical and the noncanonical. A number of stimuli can activate both pathways, and then lead to rapid and transient activation of IKK $(98,99)$. The major mechanism for auto- phagy-mediated inflammation restriction and subsequent tumour suppression might be actually through targeting NF-KB (100). Autophagy can selectively degrade IKK, which results in restriction of inducible activation of NF- $\kappa B$. More importantly, autophagic inhibition leads to IKK-NF- $\kappa B$ in malignant cells and significantly dampens cytotoxicity of GA. Thus, NF- $\kappa B$ establishes a link between autophagy and its function in suppressing both inflammation and tumour progression (98). Moreover, NF- $\kappa B$ activation prevents autophagy activation induced by inflammatory cytokines $(101,102)$ (Fig. $2 b)$.

\section{Beclin-1 interactome}

Beclin-1 the mammalian orthologue of Atg6, and myristylated serine kinase Vps15/p150, can work together to form a Beclin-1 interactome, regulating activity of Class III phosphatidylinositol 3-kinase (PI3KCIII), an orthologue of Vps34 (103,104). Beclin-1 has been demonstrated to combine with $\mathrm{PI} 3 \mathrm{KIII} / \mathrm{Vps} 34$ in an evolutionarily conserved domain (ECD), but lack of the latter leads to loss of tumour suppressor function of Beclin-1 (105). Two positive mediators of Beclin-1 interactome exist, namely ultraviolet irradiation resistanceassociated gene UVRAG and Bif-1. UVRAG interacts with Beclin-1, and Bif-1 interacts with Beclin-1 through UVRAG. Their interactions can markedly enhance PI3KC3 lipid kinase activity, thereby facilitating autophagy $(106,107)$. There also exist several Beclin-1 negative regulators. Interestingly, some anti-apoptotic Bcl-2 family members, such as Bcl-2 and $\mathrm{Bcl}-\mathrm{X}_{\mathrm{L}}$, containing four Bcl-2 homology domains $(\mathrm{BH})$, can inhibit autophagy by interacting with Beclin-1. The BH3 domain of Beclin-1 contributes to their association (108). It is suspected that Bcl-2 blocks Beclin-1 interaction with PI3KCIII, reduces PI3KCIII activity and downregulates autophagy, through either disassociating with the Beclin-1/PI3KCIII or inhibition of its activity (109) (Fig. 2c).

\section{The programmed necrosis pathways in cancer}

Ligation of death ligands such as TNF $\alpha$, TNF-related apoptosis-inducing ligand (TRAIL) and Fas ligand (FasL) to their cognate receptors results in assembly of a supramolecular platform composed of caspase- 8 , the adaptor protein FADD and receptor-interacting serinethrenoine kinase 1 (RIP1). Under normal conditions, active caspase- 8 cleaves RIP1 and inactivates it. However, caspases may be inactivated, for instance, after exposure to pancaspase inhibitor Z-VAK-fmk, or upon infection by viral strains that encode serpins. In such cases, death receptor ligation results in assembly of a 


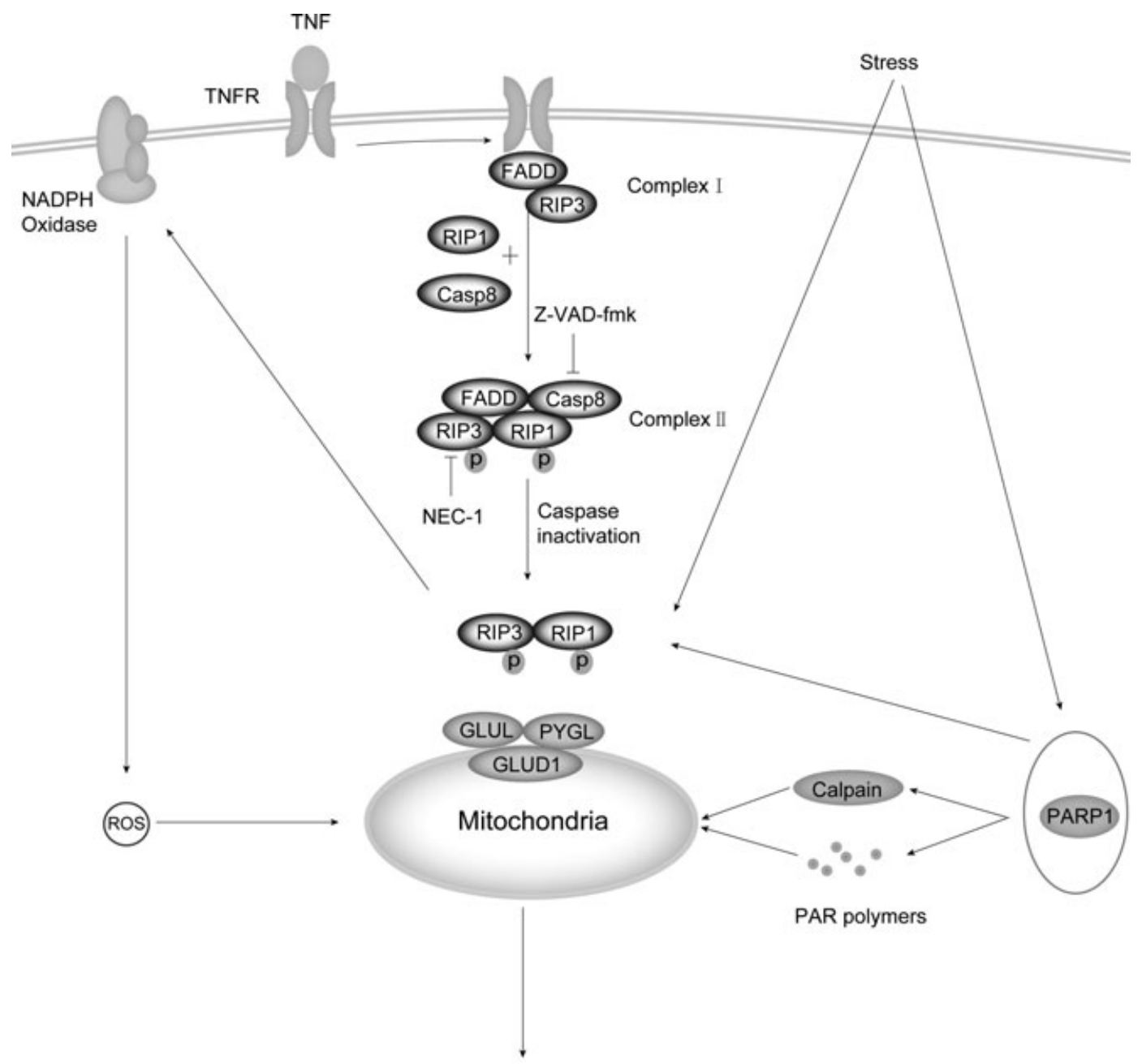

Programmed necrosis

Pro-death $\quad \longrightarrow$ other Activation $\longrightarrow$ Inactivation

Figure 3. Programmed necrosis signalling pathways in cancer.

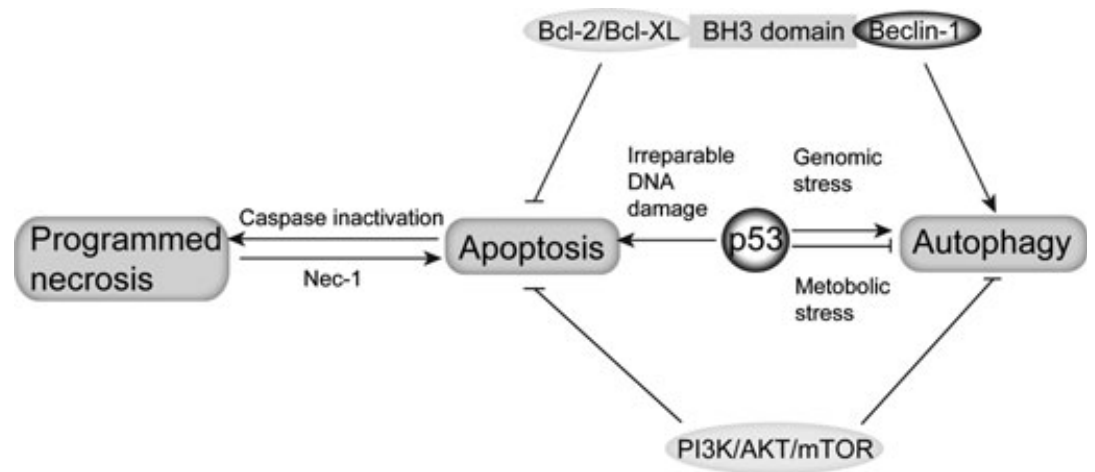

Figure 4. Cross-talk between apoptosis, autophagy and programmed necrosis. 
complex involving caspase-8, FADD, RIP1 and RIP3. Subsequently, pro-necrotic complex RIP1-RIP3 interacts with metabolic enzymes, such as glycogen phosphorylase (PYGL), glutamate-ammonia ligase (GLUL) and glutamate dehydrogenase 1 (GLUD1) to enhance metabolism, accompanied by increased reactive oxygen species' (ROS) production (110). Thus, excessive ROS can lead to mitochondrial membrane permeabilization (MMP) and subsequent programmed necrosis. There are a number of other modulators involved in the programmed necrosis modulating network including PARP1, PAR polymers, NADPH osidases and calpains. Necrotic cell death stresses can activate PARP1, which potentially induces necrosis either through activation of RIP kinases, activation of calpains (111), or by production of PAR polymers $(112,113)$. In addition, activation of death receptors or cell stress can induce interaction and activation of kinases RIP1 and RIP3, which influence mitochondria either directly or indirectly through NADPH oxidase, to induce ROS increase, thereby leading to necrosis (114-116) (Fig. 3).

\section{Conclusions and perspectives}

Programmed cell death (PCD) involves not just the traditional death module apoptosis, but multiple death programs including programmed necrosis and autophagic cell death (4). The huge increase in publications related to PCD, specially those focusing on apoptosis and autophagic pathways, has contributed to a wealth of knowledge in facilitating a better understanding of cancer pathogenesis and therapeutics (Fig. 4). Many death regulatory genes are common to more than one module; therefore, PCD should be regarded as a network of interconnected pathways comprising of the three main functional modules.

However, traditional ways of searching for drug targets and signalling pathways related to anti-cancer therapy are out of date; the emerging challenge over the next decade is to systematically assemble these components into functional molecular and cellular networks, then to use them to answer fundamental questions concerning cell processes and how malignancy reflects them. Integration of various interactome and functional relationship networks has been widely applied to reveal genomic functions in cancer cells. Cancer biologists try to realize how apoptosis, autophagy and programmed necrosis pathways could be mapped and integrated with each other, what global properties are beginning to emerge from interactome network models, and how these properties may relate to cancer and its treatment.

Even though such networks have not been mapped completely due to their high levels of complexity, data and models accumulated recently point to clear directions for the future. Recent studies have demonstrated that the best hope for targeting apoptosis and autophagy in potential therapeutic applications may lie in discovery of numbers of useful agents that are able to target physiological effects of altered key signalling pathways and even the global PCD network rather than their individual gene or protein components. Thus, the human PCD network could provide more novel insights into how these hub proteins and their PCD pathways may play crucial roles as potential drug targets in cancer treatment, at the systems level, which refer to PCD networkbased identification of new targets for drug discovery.

\section{Acknowledgements}

We are grateful to Lei-lei Fu, Shu-ya Wang and Xin Wen for their critical reviews on this manuscript. We also thank Jia-ying $\mathrm{Yu}, \mathrm{Xu}$ Zhao and Cheng-cheng Zhou for their excellent suggestions. This work was supported in part by the grants from the Young Teacher's Fund of Sichuan University (No. 2010SCU11066), the Science Foundation for Post Doctorate Research of China (No. 20110491725), and the Major State Basic Research Development Program of China (973 Program) (No. 2010cb529900).

\section{References}

1 Hanahan D, Weinberg RA (2011) Hallmarks of cancer: the next generation. Cell 144, 646-674.

2 Laubenbacher R, Hower V, Jarrah A, Torti SV, Shulaev V, Mendes P et al. (2009) A systems biology view of cancer. Biochim. Biophys. Acta 1796, 129-139.

3 Tan ML, Ooi JP, Ismail N, Moad AI, Muhammad TS (2009) Programmed cell death pathways and current antitumor targets. Pharmacol. Res. 26, 1547-1560.

4 Bialik S, Zalckvar E, Ber Y, Rubinstein AD, Kimchi A (2010) Systems biology analysis of programmed cell death. Trends Biochem. Sci. 35, 556-564.

5 Kerr JFR, Wyllie AH, Currie AR (1972) Apoptosis: a basic biological phenomenon with wide-ranging implications in tissue kinetics. Br. J. Cancer 26, 239-257.

6 Nishida K, Yamaguchi O, Otsu K (2008) Crosstalk between autophagy and apoptosis in heart disease. Circ. Res. 103, 343-351.

7 Martin SJ, Green DR (1995) Protease activation during apoptosis: death by a thousand cuts? Cell 82, 349-352.

8 Cohen GM, Sun XM, Fearnhead H, MacFarlane M, Brown DG, Snowden RT et al. (1994) Formation of large molecular weight fragments of DNA is a key committed step of apoptosis in thymocytes. J. Immunol. 153, 507-516.

9 Liu JJ, Lin M, Yu JY, Liu B, Bao JK (2011) Targeting apoptotic and autophagic pathways for cancer therapeutics. Cancer Lett. 300, 105-114.

10 Huett A, Goel G, Xavier RJ (2010) A systems biology viewpoint on autophagy in health and disease. Curr. Opin. Gastroenterol. 26, 302-309. 
11 Chen S, Rehman SK, Zhang W, Wen A, Yao L, Zhang J (2010) Autophagy is a therapeutic target in anticancer drug resistance. Biochim. Biophys. Acta 1806, 220-229.

12 Li ZY, Yang Y, Ming M, Liu B (2011) Mitochondrial ROS generation for regulation of autophagic pathways in cancer. Biochem. Biophys. Res. Commun. 414, 5-8.

13 He C, Klionsky DJ (2009) Regulation mechanisms and signaling pathways of autophagy. Annu. Rev. Genet. 43, 67-93.

14 Eisenberg-Lerner A, Bialik S, Simon HU, Kimchi A (2009) Life and death partners: apoptosis, autophagy and the cross-talk between them. Cell Death Differ. 16, 966-975.

15 Liu B, Cheng Y, Liu Q, Bao JK, Yang JM (2010) Autophagic pathways as new targets for cancer drug development. Acta Pharmacol. Sin. 31, 1154-1164.

16 Wu W, Liu P, Li J (2012) Necroptosis: an emerging form of programmed cell death. Crit. Rev. Oncol. Hematol. 82, 249-258.

17 McCall K (2010) Genetic control of necrosis - another type of programmed cell death. Curr. Opin. Cell Biol. 22, 882-888.

18 Leist M, Jaattela M (2001) Four deaths and a funeral: from caspases to alternative mechanisms. Nat. Rev. Mol. Cell Biol. 2 , 589-598.

19 Amelio I, Melino G, Knight RA (2011) Cell death pathology: cross-talk with autophagy and its clinical implications. Biochem. Biophys. Res. Commun. 414, 277-281.

20 Eum KH, Lee M (2011) Crosstalk between autophagy and apoptosis in the regulation of paclitaxel-induced cell death in v-Ha-rastransformed fibroblasts. Mol. Cell. Biochem. 348, 61-68.

21 Ghobrial IM, Witzig TE, Adjei AA (2005) Targeting apoptosis pathways in cancer therapy. Cancer J. Clin. 55, 178-194.

22 Wang SY, Yu QJ, Zhang RD, Liu B (2011) Core signaling pathways of survival/death in autophagy-related cancer networks. Int. J. Biochem. Cell Biol. 43, 1263-1266.

23 White E (2012) Deconvoluting the context-dependent role for autophagy in cancer. Nat. Rev. Cancer. 12, 401-410.

24 Kundu M, Thompson CB (2008) Autophagy: basic principles and relevance to disease. Annu. Rev. Pathol. 3, 427-455.

25 Galluzzi L, Kroemer G (2008) Necroptosis: a specialized pathway of programmed necrosis. Cell 135, 1161-1163.

26 Golstein P, Kroemer G (2007) Cell death by necrosis: towards a molecular definition. Trends Biochem. Sci. 32, 37-43.

27 Zong WX, Ditsworth D, Bauer DE, Wang ZQ, Thompson CB (2004) Alkylating DNA damage stimulates a regulated form of necrotic cell death. Genes Dev. 18, 1272-1282.

28 Agostinis P, Buytaert E, Breyssens H, Hendrickx N (2004) Regulatory pathways in photodynamic therapy induced apoptosis. Photochem. Photobiol. Sci. 3, 721-729.

29 Gonzalez-Polo RA, Boya P, Pauleau AL, Jalil A, Larochette N, Souquere $\mathrm{S}$ et al. (2005) The apoptosis/autophagy paradox: autophagic vacuolization before apoptotic death. J. Cell Sci. 118, 3091-3102.

30 Degterev A, Huang Z, Boyce M, Li Y, Jagtap P, Mizushima N et al. (2005) Chemical inhibitor of nonapoptotic cell death with therapeutic potential for ischemic brain injury. Nat. Chem. Biol. 1, $112-119$.

31 Han W, Xie J, Li L, Liu Z, Hu X (2009) Necrostatin-1 reverts shikonin-induced necroptosis to apoptosis. Apoptosis 14, 674-686.

32 Liu P, Xu B, Shen W, Zhu H, Wu W, Fu Y et al. (2012) Dysregulation of $\mathrm{TNF} \alpha$-induced necroptotic signaling in chronic lymphocytic: suppression of CYLD gene by LEF1. Leukemia. 26, 1293-1300.

33 Sayers TJ (2011) Targeting the extrinsic apoptosis signaling pathway for cancer therapy. Cancer Immunol. Immunother. 60, 1173-1180.
34 Mannick JB, Hausladen A, Liu L, Hess DT, Zeng M, Miao QX et al. (1999) Fas-induced caspase denitrosylation. Science 284, $651-654$.

35 Sun SY (2011) Understanding the role of the death receptor 5/ FADD/caspase-8 death signaling in cancer metastasis. Mol. Cell. Pharmacol. 3, 31-34.

36 Bell BD, Leverrier S, Weist BM, Newton RH, Arechiga AF Luhrs KA et al. (2008) FADD and caspase-8 control the outcome of autophagic signaling in proliferating T cells. Proc. Natl. Acad. Sci. USA 105, 16677-16682.

37 Llambi F, Green DR (2011) Apoptosis and oncogenesis: give and take in the BCL-2 family. Curr. Opin. Genet. Dev. 21, 12-20.

38 Engel T, Henshall DC (2009) Apoptosis, Bcl-2 family proteins and caspases: the ABCs of seizure-damage and epileptogenesis? IJPPP 1, 97-115.

39 Shamas-Din A, Brahmbhatt H, Leber B, Andrews DW (2011) BH3-only proteins: orchestrators of apoptosis. Biochim. Biophys. Acta 1813, 508-520.

40 Wen X, Lin ZQ, Liu B, Wei YQ (2012) Caspase-mediated programmed cell death pathways as potential therapeutic targets in cancer. Cell Prolif. 45, 217-224.

41 Zou H, Henzel WJ, Liu X, Lutschg A, Wang X (1997) Apaf-1, a human protein homologous to $C$. elegans CED-4, participates in cytochrome c-dependent activation of caspase-3. Cell 90, 405-413.

42 Li P, Nijhawan D, Budihardjo I, Srinivasula SM, Ahmad M, Alnemri ES et al. (1997) Cytochrome c and dATP-dependent formation of Apaf-1/caspase-9 complex initiates an apoptotic protease cascade. Cell 91, 479-489.

43 Kelly PN, Strasser A (2011) The role of Bcl-2 and its pro-survival relatives in tumourigenesis and cancer therapy. Cell Death Differ. 18, 1414-1424.

44 Ghavami S, Hashemi M, Ande SR, Yeganeh B, Xiao W, Eshraghi M et al. (2009) Caspase genes apoptosis and cancer: mutations within caspase genes. Am. J. Med. Genet. 46, 497-510.

45 Scaffidi C, Fulda S, Srinivasan A, Friesen C, Li F, Tomaselli KJ et al. (1998) Two CD95 (APO-1/Fas) signaling pathways. EMBO J. 17, 1675-1687.

46 Chen M, Wang J (2002) Initiator caspases in apoptosis signaling pathways. Apoptosis 7, 313-319.

47 Kurokawa M, Kornbluth S (2009) Caspases and kinases in a death grip. Cell 138, 838-854.

48 Giansanti V, Torriglia A, Scovassi AI (2011) Conversation between apoptosis and autophagy: "Is it your turn or mine?". Apoptosis 16, $321-333$.

49 Allan LA, Clarke PR (2009) Apoptosis and autophagy: regulation of caspase- 9 by Phosphorylation. FEBS J. 276, 6063-6073.

50 Bratton SB, Walker G, Srinivasula SM, Sun XM, Butterworth M, Alnemri ES et al. (2001) Recruitment, activation and retention of caspases- 9 and -3 by Apaf- 1 apoptosome and associated XIAP complexes. EMBO J. 20, 998-1009.

51 Kuida K, Haydar TF, Kuan CY, Gu Y, Taya C, Karasuyama H et al. (1998) Reduced apoptosis and cytochrome c-mediated caspase activation in mice lacking caspase-9. Cell 94, 325-337.

52 Martin MC, Allan LA, Lickrish M, Sampson C, Morrice N, Clarke PR (2005) Protein kinase A regulates caspase-9 activation by Apaf-1 downstream of cytochrome c. J. Biol. Chem. 280, 15449-15455.

53 Karin M, Greten FR (2005) NF-kappaB: linking inflammation and immunity to cancer development and progression. Nat. Rev. Immunol. 5, 749-759.

54 Nelson DE, Ihekwaba AE, Elliott M, Johnson JR, Gibney CA, Foreman BE et al. (2004) Oscillations in NF- $\kappa \mathrm{B}$ signaling control the dynamics of gene expression. Science 306, 704-708. 
55 Kühnel F, Zender L, Paul Y, Tietze MK, Trautwein C, Manns M et al. (2000) NFkappaB mediates apoptosis through transcriptional activation of Fas (CD95) in adenoviral hepatitis. J. Biol. Chem. 275, 6421-6427.

56 Karin M, Yamamoto Y, Wang QM (2004) The IKK NF-кB system: a treasure trove for drug development. Nat. Rev. Drug Discov. 3, 17-26.

57 Yin MJ, Yamamoto Y, Gaynor RB (1998) The anti-inflammatory agents aspirin and salicylate inhibit the activity of I (kappa) Bkinase-beta. Nature 396, 77-80.

58 Song JK, Jo MR, Park MH, Song HS, An BJ, Song MJ et al. (2012) Cell growth inhibition and induction of apoptosis by snake venom toxin in ovarian cancer cell via inactivation of nuclear factor kappaB and signal transducer and activator of transcription 3 . Arch. Pharm. Res. 35, 867-876.

59 Ling H, Zhang Y, Ng KY, Chew EH (2011) Pachymic acid impairs breast cancer cell invasion by suppressing nuclear factorkappaB-dependent matrix metalloproteinase-9 expression. Breast Cancer Res. Treat. 126, 609-620.

60 Kastan MB, Onyekwere O, Sidransky D, Vogelstein B, Craig RW (1991) Participation of p53 protein in the cellular response to DNA damage. Cancer Res. 51, 6304-6311.

61 Benchimol S (2001) P53-dependent pathways of apoptosis. Cell Death Differ. 8, 1049-1051.

$62 \mathrm{Yu} \mathrm{J}$, Wang Z, Kinzler KW, Vogelstein B, Zhang L (2003) PUMA mediates the apoptotic response to p53 in colorectal cancer cells. Proc. Natl. Acad. Sci. USA 100, 1931-1936.

63 Lima RT, Busacca S, Almeida GM, Gaudino G, Fennell DA, Vasconcelos MH (2011) MicroRNA regulation of core apoptosis pathways in cancer. Eur. J. Cancer 47, 163-174.

64 Garzon R, Calin GA, Croce CM (2009) MicroRNAs in cancer. Annu. Rev. Med. 60, 167-179.

65 Miller TE, Ghoshal K, Ramaswamy B, Roy S, Datta J, Shapiro CL et al. (2008) MicroRNA-221/222 confers tamoxifen resistance in breast cancer by targeting p27Kip1. J. Biol. Chem. 283, 29897-29903.

66 Linnstaedt SD, Gottwein E, Skalsky RL, Luftig MA, Cullen BR (2010) Virally induced cellular microRNA miR-155 plays a key role in B-cell immortalization by Epstein-Barr virus. J. Virol. 84, $11670-11678$

67 Wang Y, Lee CG (2009) MicroRNA and cancer - focus on apoptosis. J. Cell Mol. Med. 13, 12-23.

68 Croce CM (2009) Causes and consequences of microRNA dysregulation in cancer. Nat. Rev. Genet. 10, 704-714.

69 Tsang WP, Kwok TT (2008) Let-7a microRNA suppresses therapeutics-induced cancer cell death by targeting caspase-3. Apoptosis 13, 1215-1222.

70 Esau CC, Monia BP (2007) Therapeutic potential for microRNAs. Adv. Drug Deliver. Rev. 59, 101-114.

71 Kamada Y, Funakoshi T, Shintani T, Nagano K, Ohsumi M, Ohsumi Y (2000) Tor-mediated induction of autophagy via an Apg1 protein kinase complex. J. Cell Biol. 150, 1507-1513.

72 Hara T, Takamura A, Kishi C, Iemura S, Natsume T, Guan JL et al. (2008) FIP200, a uLK-interacting protein, is required for autophagosome formation in mammalian cells. J. Cell Biol. 181, 497-510.

73 Hosokawa N, Hara T, Kaizuka T, Kishi C, Takamura A, Miura Y et al. (2009) Nutrient-dependent mTORC1 association with the uLK1-Atg13-FIP200 complex required for autophagy. Mol. Biol. Cell 7, 1981-1991.

74 White E, DiPaola RS (2009) The double-edged sword of autophagy modulation in cancer. Clin. Cancer Res. 15, 5308-5316.

75 Weinstein IB (2002) Addiction to oncogenes - the Achilles heal of cancer. Science 297, 63-64.
76 Weinstein IB, Joe AK (2006) Mechanisms of disease: oncogene addiction - a rationale for molecular targeting in cancer therapy. Nat. Clin. Pract. Oncol. 3, 448-457.

77 Yap MD, Garrett MD, Walton MI, Raynaud F, de Bono JS, Workman P (2008) Targeting the PI3K-AKT-mTOR pathway: progress, pitfalls, and promises. Curr. Opin. Pharmacol. 8, 393412.

78 Crabbe T, Welham MJ, Ward SG (2007) The PI3K inhibitor arsenal: choose your weapon!. Trends Biochem. Sci. 32, 450-456.

79 Staal SP (1987) Molecular cloning of the akt oncogene and its human homologues AKT1 and AKT2: amplification of AKT1 in a primary human gastric adenocarcinoma. Proc. Natl. Acad. Sci. USA 84, 5034-5037.

80 Loewith R, Jacinto E, Wullschleger S, Lorberg A, Crespo JL, Bonenfant D et al. (2002) Two TOR complexes, only one of which is rapamycin sensitive, have distinct roles in cell growth control. Mol. Cell 10, 457-468.

81 Zhang BH, Guan KL (2000) Activation of B-Raf kinase requires phosphorylation of the conserved residues Thr598 and Ser601. EMBO J. 19, 5429-5439.

82 Akca H, Demiray A, Aslan M, Acikbas I, Tokgun O (2012) tumour suppressor PTEN enhanced enzyme activity of GPx, SOD and catalase by suppression of PI3K/AKT pathway in non-small cell lung cancer cell lines. J. Enzyme Inhib. Med. Chem., doi: 10.3109/14756366.2011.654114.

83 Brugarolas J, Lei K, Hurley RL, Manning BD, Reiling JH, Hafen E et al. (2004) Regulation of mTOR function in response to hypoxia by REDD1 and the TSC1/TSC 2 tumor suppressor complex. Genes Dev. 18, 2893-2904.

84 Lee JTJ, McCubrey JA (2002) Targeting the Raf kinase cascade in cancer therapy - novel molecular targets and therapeutic strategies. Expert Opin. Ther. Tar. 6, 659-678.

85 Rojas AM, Fuentes G, Rausell A, Valencia A (2012) The Ras protein superfamily: evolutionary tree and role of conserved amino acids. J. Cell Biol. 196, 189-201.

86 Jin Y, Shima Y, Furu M, Aoyama T, Nakamata T, Nakayama T et al. (2010) Absence of oncogenic mutations of RAS family genes in soft tissue sarcomas of 100 Japanese patients. Anticancer Res. 30, 245-251.

87 Cantrell DA (2003) GTPases and T cell activation. Immunol. Rev. 192, 122-130.

88 Marais R, Light Y, Paterson HF, Marshall CJ (1995) Ras recruits Raf-1 to the plasma membrane for activation by tyrosine phosphorylation. EMBO J. 14, 3136-3145.

89 Schlesinger TK, Fanger GR, Yujiri T, Johnson GL (1998) The TAO of MEKK. Front. Biosci. 3, 1181-1186.

90 Crighton D, Wilkinson S, O'Prey J, Syed N, Smith P, Harrison PR et al. (2006) DRAM, a p53-induced modulator of autophagy, is critical for apoptosis. Cell 126, 121-134.

91 Kroemer G, Galluzzi L, Vandenabeele P, Abrams J, Alnemri ES, Baehrecke EH et al. (2009) Classification of cell death: recommendations of the Nomenclature Committee on Cell Death 2009. Cell Death Differ. 16, 3-11.

92 Duran A, Serrano M, Leitges M, Flores JM, Picard S, Brown JP et al. (2004) The atypical PKC-interacting protein p62 is an important mediator of RANK-activated osteoclastogenesis. Dev. Cell 6, 303-309.

93 Budanov AV, Karin M (2008) p53 target genes sestrin1 and sestrin2 connect genotoxic stress and mTOR signaling. Cell 134, 451-460.

94 Maiuri MC, Malik SA, Morselli E, Kepp O, Criollo A, Mouchel PL et al. (2009) Stimulation of autophagy by the p53 target gene Sestrin2. Cell Cycle 8, 1571-1576. 
95 Tasdemir E, Maiuri MC, Galluzzi L, Vitale I, Djavaheri-Mergny M, D'Amelio M et al. (2008) Regulation of autophagy by cytoplasmic p53. Nat. Chem. Biol. 10, 676-687.

96 Nakano K, Vousden KH (2001) PUMA, a novel proapoptotic gene, is induced by p53. Mol. Cell 7, 683-694.

97 Zhang X, Rielland M, Yalcin S, Ghaffari S (2011) Regulation and function of FoxO transcription factors in normal and cancer stem cells: what have we learned? Curr. Drug Targets 12, 1267-1283.

98 Jiang Q, Wang Y, Li T, Shi K, Li Z, Ma Y et al. (2011) Heat shock protein 90-mediated inactivation of nuclear factor-kappaB switches autophagy to apoptosis through becn1 transcriptional inhibition in selenite-induced NB4 cells. Mol. Biol. Cell 22, 1167-1180.

99 Degenhardt K, Mathew R, Beaudoin B, Bray K, Anderson D, Chen $\mathrm{G}$ et al. (2006) Autophagy promotes tumor cell survival and restricts necrosis, inflammation, and tumorigenesis. Cancer Cell 10, 51-64.

100 Qing G, Yan P, Qu Z, Liu H, Li H, Xiao G (2007) Hsp90 regulates processing of NF-kB2 p100 involving protection of NF-kBinducing kinase (NIK) from autophagy-mediated degradation. Cell Res. 17, 520-530.

101 Djavaheri-Mergny M, Amelotti M, Mathieu J, Besancon F, Bauvy C, Souquere S (2006) NF-kB activation represses TNF a-induced autophagy. J. Biol. Chem. 281, 30373-30382.

102 Fu LL, Wen X, Bao JK, Liu B (2012) MicroRNA-modulated autophagic signaling networks in cancer. Int. J. Biochem. Cell Biol. 44, 733-736.

103 Stack JH, DeWald DB, Takegawa K, Emr SD (1995) Vesiclemediated protein transport: regulatory interactions between the Vps15 protein kinase and the Vps34 PtdIns 3-kinase essential for protein sorting to the vacuole in yeast. J. Cell Biol. 129, 321-334.

104 Kihara A, Noda T, Ishihara N, Ohsumi Y (2001) Two distinct Vps34 phosphatidylinositol 3-kinase complexes function in autophagy and carboxypeptidase $\mathrm{Y}$ sorting in Saccharomyces cerevisiae. J. Cell Biol. 152, 519-530.

105 Furuya N, Yu J, Byfield M, Pattingre S, Levine B (2005) The evolutionarily conserved domain of Beclin-1 is required for Vps34 binding, autophagy and tumor-suppressor function. Autophagy 1, 46-52.
106 Liang C, Feng P, Ku B, Dotan I, Canaani D, Oh BH et al. (2006) Autophagic and tumour suppressor activity of a novel Beclin-1binding protein UVRAG. Nat. Cell Biol. 8, 688-699.

107 Takahashi Y, Coppola D, Matsushita N, Cualing HD, Sun M, Sato Y et al. (2007) Bif-1 interacts with Beclin 1 through UVRAG and regulates autophagy and tumorigenesis. Nat. Cell Biol. 9, 1142-1151.

108 He C, Levine B (2010) The Beclin 1 interactome. Curr. Opin. Cell Biol. 22, 140-149.

109 Morselli E, Galluzzi L, Kepp O, Vicencio JM, Criollo A, Maiuri MC et al. (2009) Anti- and pro-tumor functions of autophagy. Biochem. Biophys. Acta 1793, 1524-1532.

110 Zhang DW, Shao J, Lin J, Zhang N, Lu BJ, Lin SC et al. (2009) RIP3, an energy metabolism regulator that switches TNF-induced cell death from apoptosis to necrosis. Science 325, 332-336.

111 Moubarak RS, Yuste VJ, Artus C, Bouharrour A, Greer PA, Menissier-de Murcia J et al. (2007) Sequential activation of poly (ADP-ribose) polymerase 1, calpains, and Bax is essential in apoptosis-inducing factor-mediated programmed necrosis. Mol. Cell. Biol. 27, 4844-4862.

112 Xu Y, Huang S, Liu ZG, Han J (2006) Poly (ADP-ribose) polymer-ase-1 signaling to mitochondria in necrotic cell death requires RIP1/TRAF2-mediated JNK1 activation. J. Biol. Chem. 281, 8788 -8795 .

113 Hassa PO (2009) The molecular "Jekyll and Hyde" duality of PARP1 in cell death and cell survival. Front. Biosci. 14, 72-111.

114 Kim YS, Morgan MJ, Choksi S, Liu ZG (2007) TNF-induced activation of the Nox1 NADPH oxidase and its role in the induction of necrotic cell death. Mol. Cell 26, 675-687.

115 Cho YS, Challa S, Moquin D, Genga R, Ray TD, Guildford M et al. (2009) Phosphorylation-driven assembly of the RIP1-RIP3 complex regulates programmed necrosis and virus-induced inflammation. Cell 137, 1112-1123.

116 He S, Wang L, Miao L, Wang T, Du F, Zhao L et al. (2009) Receptor interacting protein kinase-3 determines cellular necrotic response to TNF-alpha. Cell 137, 1100-1111. 